OPEN ACCESS

Edited by:

Christian Hansel,

University of Chicago, USA

Reviewed by:

Constance Scharff,

Free University of Berlin, Germany

*Correspondence:

Dirk Schubert

d.schubert@donders.ru.n

Received: 27 May 2016 Accepted: 10 January 2017 Published: 25 January 2017

Citation:

Negwer M and Schubert D (2017)

Talking Convergence: Growing Evidence Links FOXP2 and Retinoic

Acid in Shaping Speech-Related

Motor Circuitry.

Front. Neurosci. 11:19.

doi: 10.3389/fnins.2017.00019

\section{Talking Convergence: Growing Evidence Links FOXP2 and Retinoic Acid in Shaping Speech-Related Motor Circuitry}

\author{
Moritz Negwer ${ }^{1,2}$ and Dirk Schubert ${ }^{2 *}$ \\ ${ }^{1}$ Max Planck Institute for Psycholinguistics, Nijmegen, Netherlands, ${ }^{2}$ Department of Cognitive Neuroscience, Radboud \\ University Medical Center, Donders Institute for Brain, Cognition, and Behaviour, Nijmegen, Netherlands
}

Keywords: FoxP2, retinoic acid, motor circuits, speech disorder, striatum, dopamine, RARB, globus pallidus

\section{A commentary on}

FOXP2 drives neuronal differentiation by interacting with retinoic acid signaling pathways by Devanna, P., Middelbeek, J., and Vernes, S. C. (2014). Front. Cell. Neurosci. 8:305. doi: 10.3389/ fncel.2014.00305

FOXP2 was the first identified monogenic cause of a speech disorder (for review see Graham et al., 2015). However, it remains to be answered how it affects the development of speech related neuronal circuits and what the relevant molecular pathways may be. Devanna et al. (2014) reported a direct interaction between FOXP2 and Retinoic Acid (RA), an important signaling molecule in brain development and neuronal differentiation, in a cell model. What could this finding mean for our understanding of a language-ready brain?

Mounting evidence from diverse fields such as linguistics, genetics, brain development, and cellular neurophysiology suggests that the brain's motor circuitry might be the key to the conundrum of language disorders. Human patients with FOXP2 mutations show prominent motor learning deficits at the root of their developmental verbal dyspraxia diagnosis, which is reflected in mouse models of Foxp2 loss (for review see Deriziotis and Fisher, 2013; Graham et al., 2015). Interestingly, in mice with dysregulated RA signaling, similar motor learning impairments have been found (for review see Duester, 2013). Retinoic acid has several prominent roles in brain development and function, for example as a diffusible signaling molecule that changes gene expression via nuclear retinoic acid receptors (RARs, RORs, and RXRs; for review see Maden, 2007).

Devanna et al. (2014) demonstrated a direct interaction between FOXP2 and RA signaling in a human neuroblastoma cell line (SH-S5Y5), in which RA exposure initiates differentiation into a dopaminergic-neuron like state (Korecka et al., 2013). When the researchers compared FOXP2 overexpression to RA treatment they found an interesting convergence: In both cases, the cells differentiated from their previously proliferative state into a more neuron-like state and showed elevated expression of RA signaling-related genes, specifically the receptor RARß.

A recent review of the same group (van Rhijn and Vernes, 2015) suggests that the motorlearning deficits found in carriers of FoxP2 mutations might be mediated by defects in RA signaling, also in humans. Interestingly, FoxP2 and RA signaling have also been found (separately) to be involved in vocal production learning in a songbird model (Denisenko-Nehrbass et al., 2000; Olson et al., 2011; Roeske et al., 2014; Wohlgemuth et al., 2014). Even though direct evidence of synergies between FoxP2 and RA signaling is still lacking beyond cell models, the hypothesis that they are 
parts of the same regulatory network (e.g. Benítez-Burraco and Boeckx, 2014; van Rhijn and Vernes, 2015) would fit well with a number of findings, some of which we will address in the following commentary.

\section{STRIATAL DEVELOPMENT: DO FoxP2 AND RA CONVERGE ON SPECIFIC CELL TYPES?}

The canonical cortico-basal-ganglia-thalamic motor circuit is thought to be crucial for the motor aspects of vocal production. Interestingly, in this canonical circuit FoxP2 (refers to the gene across vertebrate species) and RA receptor expression overlap in several regions (Figures 1A,B). An especially illustrative region in this regard is the striatum, a hub of the motor circuitry that is known to be involved in motor sequencing in mammals (Kravitz and Kreitzer, 2012; Friend and Kravitz, 2014) and also in vocal production learning in songbirds (Bolhuis et al., 2010; Scharff and Petri, 2011). Available data indicates both FoxP2 expression and RA in the development and function of the striatum (van Rhijn and Vernes, 2015).

In the developing rodent striatum, two layers of progenitor cells in the ventricular and subventricular zone (SVZ) generate the medium spiny neurons (MSNs), the main cell type of the striatum (Figure 1B). Early during striatal development, a mixed population of progenitor cells in the SVZ starts producing RA, concomitant with the start of FoxP2 and RARß expression in the same region (Li et al., 2000; Ferland et al., 2003; Molotkova et al., 2007; Liao et al., 2008; Garcia-Calero et al., 2015). In general, RA signaling is involved very early in the spatial patterning of the brain, starting with the formation of the telencephalic vesicle; however the precise extent has been controversially discussed (Siegenthaler et al., 2009; Chatzi et al., 2011, 2013; Duester, 2013). More importantly for motor circuit development, RA signaling is involved in the patterning of the striatum and striatonigral projections (Rataj-Baniowska et al., 2015) as well as migration of interneurons from the Ganglionic Eminences (that also produce MSNs) to the cortex (Crandall et al., 2011).

Within striatal MSNs, mouse studies imply an interesting convergence of FoxP2 and RA signaling onto a single cell population, namely D1R-MSNs ("direct pathway" neurons) of the dorsolateral striatum (Figure 1B). In mice lacking RARß, the progenitor population prematurely differentiates, specifically reducing the final cell numbers of D1R-MSNs (Rataj-Baniowska et al., 2015). Interestingly, RAR $\beta$ was also one of the key RA receptors found to be affected in the human neuroblastoma cell study of Devanna et al. (2014). In mice lacking RARß, levels of the D1R-linked signal transduction protein Darpp-32 are greatly reduced (Liao et al., 2008). This is of interest not only because D1R-MSNs preferentially express FoxP2, but also because FoxP2 mutant mouse embryos likewise show strongly reduced Darpp32 expression levels (Vernes et al., 2011, see supplementary material). One may therefore hypothesize that FoxP2 and RA signaling pathways converge in the development of the D1R-MSNs cell class in the dorsolateral striatum (Figure 1B), impacting the motor circuit's "direct pathway".

If these hypotheses are applied to a computational model of motor sequencing (Morita et al., 2012; Morita, 2014), several possible consequences emerge. On the circuit-function level, FoxP2 and RA disruptions would impair D1R-MSNs function, and hence the "go" signal in motor control (Sippy et al., 2015, Figure 1B). Furthermore, FoxP2 mutations may
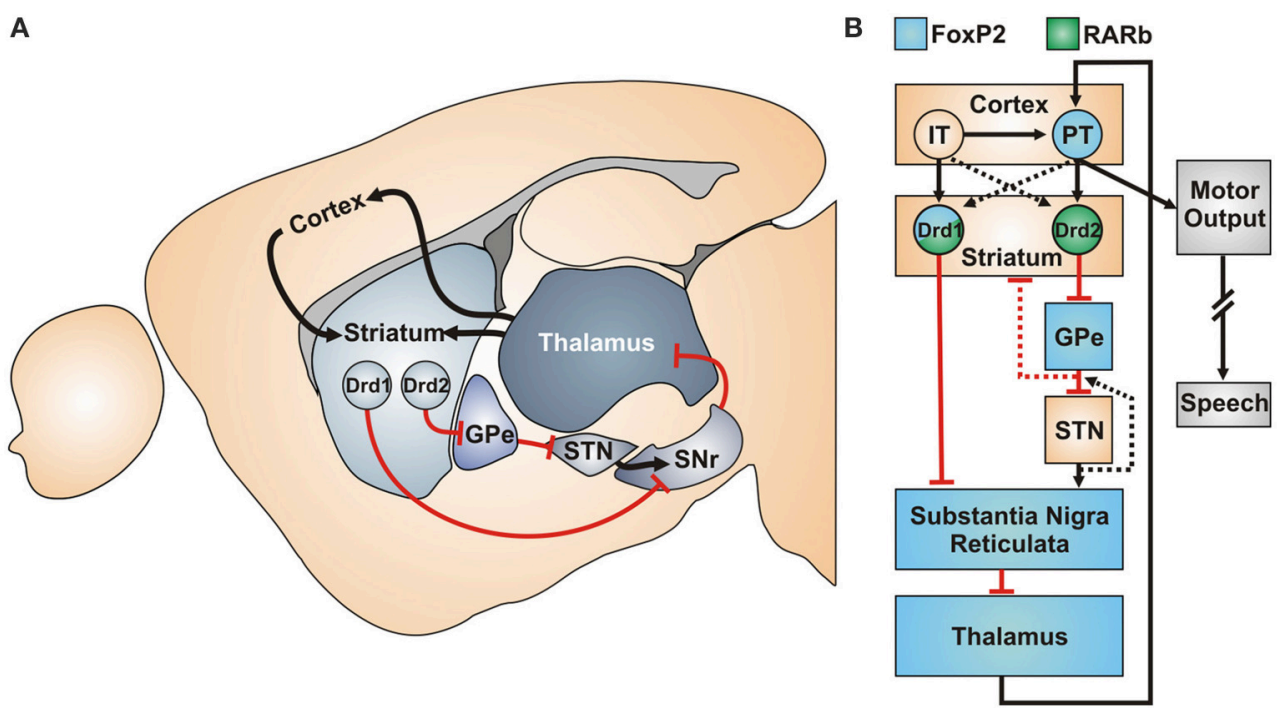

FIGURE 1 | Canonical cortico-basal-ganglia-thalamic circuit of the motor system (A) Sagittal view of the mouse motor system with excitatory (black) and inhibitory projections (red) connections. (B) Functional model (based on Morita 2014) of the motor sequencing circuitry with FoxP2 and RARb expression. IT, Intratelencephalic neurons of the cortical layer V; PT, Pyramidal tract "motor neurons" of layer Vb; Drd1/Drd2, Striatal dopamine-receptor 1/2 expressing MSNs; GPe, Globus Pallidus External; STN, Subthalamic nucleus; SNr, Substantia nigra, pars reticulata. 
affect inhibitory feedback to the striatum via a functionally defined population projecting from the Globus Pallidus Externa back to the striatum (Abdi et al., 2015; Dodson et al., 2015; Mallet et al., 2016), leading to additional defects in the "stop" motor control. Interestingly, a recent study found Foxp2 to regulate the development of the projection patterns of thalamic nuclei, another key integrative part of the motor circuitry (Ebisu et al., 2016).

\section{DOWNSTREAM BEHAVIORAL EFFECTS: DO SIMILAR PHENOTYPES IMPLY CONVERGENT MECHANISMS?}

In mice, Foxp2 loss impairs vocalizations after birth (e.g. Castellucci et al., 2016; Chen et al., 2016). However, mouse vocalizations are thought to lack a learning component, a key factor in human speech (see French and Fisher, 2014 for a review). In male zebra finches, a vocalization learning model, FoxP2 is expressed throughout the song system (Haesler et al., 2004, 2007; Scharff and Petri, 2011; Mendoza et al., 2015). Expression is especially high in the song-learning related area $\mathrm{X}$ of the striatum at the time when songs are acquired (Haesler et al., 2004; Thompson et al., 2013), and FoxP2 knockdown during this period disrupts social modulation of song variability (Murugan et al., 2013). Similar to the mouse striatal network, FoxP2 knockdown in the juvenile zebra finch leads to specific reductions of D1R and Darpp-32 expression in the dorsolateral striatum, specifically in area X (Denisenko-Nehrbass et al., 2000; Haesler et al., 2004, 2007; Olson et al., 2011; Murugan et al., 2013; Roeske et al., 2014). It should be noted that in the songbird striatum, D1R and D2R expression in MSNs overlap to a greater degree than in the mouse (Kubikova et al., 2010). Furthermore, striatal RA signaling plays an important role in the maintenance of birdsong: RA-producing enzymes are located in projection axons to area X, where the MSN-like neurons in turn express RA receptors. Functionally, RA may be important for balancing the input to area $\mathrm{X}$ neurons from vocal motor pathway (stereotyped song) versus anterior forebrain pathway (variable song) vocalization centers (Roeske et al., 2014; Wohlgemuth et al., 2014).

\section{REFERENCES}

Abdi, A., Mallet, N., Mohamed, F. Y., Sharott, A., Dodson, P. D., Nakamura, K. C., et al. (2015). Prototypic and arkypallidal neurons in the dopamine-intact external globus pallidus. J. Neurosci. 35, 6667-6688. doi: 10.1523/JNEUROSCI. 4662-14.2015

Benítez-Burraco, A., and Boeckx, C. (2014). FOXP2, retinoic acid, and language: a promising direction. Front. Cell. Neurosci. 8:387. doi: 10.3389/fncel.2014. 00387

Bolhuis, J. J., Okanoya, K., and Scharff, C. (2010). Twitter evolution: converging mechanisms in birdsong and human speech. Nat. Rev. Neurosci. 11, 747-759. doi: 10.1038/nrn2931

Castellucci, G. A., McGinley, M. J., and McCormick, D. A. (2016). Knockout of Foxp2 disrupts vocal development in mice. Sci. Rep. 6:23305. doi: 10.1038/srep 23305

\section{FoxP2 AND RA: SYNERGY IN A LARGER REGULATORY NETWORK FOR NEURONAL CONNECTIVITY?}

On the molecular level, the gene networks regulated by FoxP2 and RA signaling might overlap in specific parts of the motor circuitry. It is important to separate developmental effects from on-line functional effects: Developmental defects might lead to an impaired network setup (e.g. a smaller and miswired MSN population), while functional effects might impair the learning and function even of healthy networks (e.g. failure to balance synaptic inputs to MSNs). Furthermore, it should be noted that both FoxP2 and RA are broad regulators of large gene networks, also outside the motor circuitry.

In this context, a recent study is of particular interest: Chen et al. (2016) found that Foxp2 loss was associated with defects in dendritic spine formation in striatal neurons via de-repression of the autism risk gene Mef2C, leading to defects in corticostriatal connectivity. Research in a different murine cell model suggests that RA treatment indirectly interacts with Mef2C to specify a neuronal fate, via the transcription factor Sp1 (Elmi et al., 2007). It would therefore be highly interesting to see whether Foxp2, RA, $\mathrm{Mef} 2 \mathrm{C}$, and Sp1 are all part of the same regulatory network and influence the development of MSN connectivity.

Thus, with their finding of synergies between FOXP2 and RA in a cell model Devanna et al. (2014) made an important first step. Other studies provide indirect evidence that FoxP2 and RA signaling genes could be part of the same regulatory network and co-influence development and function of the speech-motor control circuits, especially the striatum. However, a direct proof beyond cell models is still lacking. Hence future studies in adequate animal models will have to confirm this synergy on the neuronal circuit level, also considering the more extensive regulatory molecular network affecting the development and functioning of speech-motor control circuits.

\section{AUTHOR CONTRIBUTIONS}

DS and MN both reviewed the current literature, wrote the manuscript and prepared the figures with equal contributions.

Chatzi, C., Brade, T., and Duester, G. (2011). Retinoic acid functions as a key GABAergic differentiation signal in the basal ganglia. PLoS Biol. 9:e1000609. doi: 10.1371/journal.pbio.1000609

Chatzi, C., Cunningham, T. J., and Duester, G. (2013). Investigation of retinoic acid function during embryonic brain development using retinaldehyderescued Rdh10 knockout mice. Dev. Dyn. 242, 1056-1065. doi: 10.1002/dvdy. 23999

Chen, Y. C., Kuo, H. Y., Bornschein, U., Takahashi, H., Chen, S. Y., Lu, K. M., et al. (2016). Foxp2 controls synaptic wiring of corticostriatal circuits and vocal communication by opposing Mef2c. Nat. Neurosci. 19, 1513-1522. doi: $10.1038 / \mathrm{nn} .4380$

Crandall, J. E., Goodman, T., McCarthy, D. M., Duester, G., Bhide, P. G., Dräger, U. C., et al. (2011). Retinoic acid influences neuronal migration from the ganglionic eminence to the cerebral cortex. J. Neurochem. 119, 723-735. doi: $10.1111 / \mathrm{j} .1471-4159.2011 .07471 . \mathrm{x}$ 
Denisenko-Nehrbass, N. I., Jarvis, E., Scharff, C., Nottebohm, F., and Mello, C. V. (2000). Site-specific retinoic acid production in the brain of adult songbirds. Neuron 27, 359-370. doi: 10.1016/S0896-6273(00)00043-X

Deriziotis, P., and Fisher, S. E. (2013). Neurogenomics of speech and language disorders: the road ahead. Genome Biol. 14:204. doi: 10.1186/gb-2013-14-4-204

Devanna, P., Middelbeek, J., and Vernes, S. C. (2014). FOXP2 drives neuronal differentiation by interacting with retinoic acid signaling pathways. Front. Cell. Neurosci. 8:305. doi: 10.3389/fncel.2014.00305

Dodson, P. D., Larvin, J. T., Duffell, J. M., Garas, F. N., Doig, N. M., Kessaris, N., et al. (2015). Distinct developmental origins manifest in the specialized encoding of movement by adult neurons of the external globus pallidus. Neuron 86, 501-513. doi: 10.1016/j.neuron.2015.03.007

Duester, G. (2013). Retinoid signaling in control of progenitor cell differentiation during mouse development. Semin. Cell Dev. Biol. 24, 694-700. doi: 10.1016/j.semcdb.2013.08.001

Ebisu, H., Iwai-Takekoshi, L., Fujita-Jimbo, E., Momoi, T., and Kawasaki, H. (2016). Foxp2 regulates identities and projection patterns of thalamic nuclei during development. Cereb. Cortex. doi: 10.1093/cercor/bhw187. [Epub ahead of Print].

Elmi, M., Faigle, R., Yang, W., Matsumoto, Y., Rosenqvist, E., and Funa, K. (2007). Mechanism of MASH1 induction by ASK1 and ATRA in adult neural progenitors. Mol. Cell. Neurosci. 36, 248-259. doi: 10.1016/j.mcn.2007. 07.001

Ferland, R. J., Cherry, T. J., Preware, P. O., Morrisey, E. E., and Walsh, C. A. (2003). Characterization of Foxp2 and Foxp1 mRNA and protein in the developing and mature brain. J. Comp. Neurol. 460, 266-279. doi: 10.1002/cne.10654

French, C. A., and Fisher, S. E. (2014). What can mice tell us about Foxp2 function? Curr. Opin. Neurobiol. 28C, 72-79. doi: 10.1016/j.conb.2014.07.003

Friend, D. M., and Kravitz, A. V. (2014). Working together: basal ganglia pathways in action selection. Trends Neurosci. 37, 301-303. doi: 10.1016/j.tins. 2014.04.004

Garcia-Calero, E., Botella-Lopez, A., Bahamonde, O., Perez-Balaguer, A., and Martinez, S. (2015). FoxP2 protein levels regulate cell morphology changes and migration patterns in the vertebrate developing telencephalon. Brain Struct. Funct. 221, 2905-2917. doi: 10.1007/s00429-015-1079-7

Graham, S. A., Deriziotis, P., and Fisher, S. E. (2015). Insights into the genetic foundations of human communication. Neuropsychol. Rev. 25, 3-26. doi: 10.1007/s11065-014-9277-2

Haesler, S., Rochefort, C., Georgi, B., Licznerski, P., Osten, P., and Scharff, C. (2007). Incomplete and inaccurate vocal imitation after knockdown of FoxP2 in songbird basal ganglia nucleus area X. PLoS Biol. 5:e321. doi: 10.1371/journal.pbio.0050321

Haesler, S., Wada, K., Nshdejan, A., Morrisey, E. E., Lints, T., Jarvis, E. D., et al. (2004). FoxP2 expression in avian vocal learners and non-learners. J. Neurosci. 24, 3164-3175. doi: 10.1523/JNEUROSCI.4369-03.2004

Korecka, J. A., van Kesteren, R. E., Blaas, E., Spitzer, S. O., Kamstra, J. H., Smit, A. B., et al. (2013). Phenotypic characterization of retinoic acid differentiated SH-SY5Y cells by transcriptional profiling. PLoS ONE 8:e63862. doi: 10.1371/journal.pone.0063862

Kubikova, L., Wada, K., and Jarvis, E. D. (2010). Dopamine receptors in a songbird brain. J. Comp. Neurol. 518, 741-769. doi: 10.1002/cne.22255

Li, H., Wagner, E., McCaffery, P., Smith, D., Andreadis, A., and Dräger, U. C. (2000). A retinoic acid synthesizing enzyme in ventral retina and telencephalon of the embryonic mouse. Mech. Dev. 95, 283-289. doi: 10.1016/S09254773(00)00352-X

Liao, W. L., Tsai, H. C., Wang, H. F., Chang, J., Lu, K. M., Wu, H. L., et al. (2008). Modular patterning of structure and function of the striatum by retinoid receptor signaling. Proc. Natl. Acad. Sci. U.S.A. 105, 6765-6770. doi: 10.1073/ pnas.0802109105

Maden, M. (2007). Retinoic acid in the development, regeneration and maintenance of the nervous system. Nat. Rev. Neurosci. 8, 755-765. doi: $10.1038 / \mathrm{nrn} 2212$

Mallet, N., Schmidt, R., Leventhal, D., Chen, F., Amer, N., Boraud, T., et al. (2016). Arkypallidal cells provide a Stop signal to Striatum. Neuron 89, 308-316. doi: 10.1016/j.neuron.2015.12.017
Mendoza, E., Tokarev, K., Düring, D. N., Retamosa, E. C., Weiss, M., Arpenik, N., et al. (2015). Differential coexpression of FoxP1, FoxP2, and FoxP4 in the Zebra Finch (Taeniopygia guttata) song system. J. Comp. Neurol. 523, 1318-1340. doi: $10.1002 / \mathrm{cne} .23731$

Molotkova, N., Molotkov, A., and Duester, G. (2007). Role of retinoic acid during forebrain development begins late when Raldh3 generates retinoic acid in the ventral subventricular zone. Dev. Biol. 303, 601-610. doi: 10.1016/j.ydbio.2006.11.035

Morita, K. (2014). Differential cortical activation of the striatal direct and indirect pathway cells: reconciling the anatomical and optogenetic results by using a computational method. J. Neurophysiol. 112, 120-146. doi: 10.1152/jn. 00625.2013

Morita, K., Morishima, M., Sakai, K., and Kawaguchi, Y. (2012). Reinforcement learning: computing the temporal difference of values via distinct corticostriatal pathways. Trends Neurosci. 35, 457-467. doi: 10.1016/j.tins.2012.04.009

Murugan, M., Harward, S., Scharff, C., and Mooney, R. (2013). Diminished FoxP2 levels affect dopaminergic modulation of corticostriatal signaling important to song variability. Neuron 80, 1464-1476. doi: 10.1016/j.neuron.2013.09.021

Olson, C. R., Rodrigues, P. V., Jeong, J. K., Prahl, D. J., and Mello, C. V. (2011). Organization and development of zebra finch HVC and paraHVC based on expression of $\mathrm{zRalDH}$, an enzyme associated with retinoic acid production. $J$. Comp. Neurol. 519, 148-161. doi: 10.1002/cne.22510

Rataj-Baniowska, M., Niewiadomska-Cimicka, A., Paschaki, M., Szyszka-Niagolov, M., Carramolino, L., Torres, M., et al. (2015). Retinoic acid receptor controls development of striatonigral projection neurons through FGFdependent and Meis1-dependent mechanisms. J. Neurosci. 35, 14467-14475. doi: 10.1523/JNEUROSCI.1278-15.2015

Roeske, T. C., Scharff, C., Olson, C. R., Nshdejan, A., and Mello, C. V. (2014). Long-distance retinoid signaling in the zebra finch brain. PLOS ONE 9:e111722. doi: 10.1371 /journal.pone.0111722

Scharff, C., and Petri, J. (2011). Evo-devo, deep homology and FoxP2: implications for the evolution of speech and language. Philos. Trans. R. Soc. Lond. B. Biol. Sci. 366, 2124-2140. doi: 10.1098/rstb.2011.0001

Siegenthaler, J. A., Ashique, A. M., Zarbalis, K., Patterson, K. P., Hecht, J. H., Kane, M. A., et al. (2009). Retinoic acid from the meninges regulates cortical neuron generation. Cell 139, 597-609. doi: 10.1016/j.cell.2009.10.004

Sippy, T., Lapray, D., Crochet, S., and Petersen, C. C. (2015). Cell-type-specific sensorimotor processing in striatal projection neurons during goal-directed behavior. Neuron 88, 298-305. doi: 10.1016/j.neuron.2015.08.039

Thompson, C. K., Schwabe, F., Schoof, A., Mendoza, E., Gampe, J., Rochefort, C., et al. (2013). Young and intense: FoxP2 immunoreactivity in Area X varies with age, song stereotypy, and singing in male zebra finches. Front. Neural Circuits 7:24. doi: 10.3389/fncir.2013.00024

van Rhijn, J. R., and Vernes, S. C. (2015). Retinoic acid signaling: A new piece in the spoken language puzzle. Front. Psychol. 6:1816. doi: 10.3389/fpsyg.2015.01816

Vernes, S. C., Oliver, P. L., Spiteri, E., Lockstone, H. E., Puliyadi, R., Taylor, J. M., et al. (2011). Foxp2 regulates gene networks implicated in neurite outgrowth in the developing brain. PLoS Genet. 7:e1002145. doi: 10.1371/journal.pgen.1002145

Kravitz, A. V., and Kreitzer, A. C. (2012). Striatal Mechanisms Underlying Movement, Reinforcement, and Punishment. Physiology 27, 167-177. doi: 10.1152/physiol.00004.2012

Wohlgemuth, S., Adam, I., and Scharff, C. (2014). FoxP2 in songbirds. Curr. Opin. Neurobiol. 28, 86-93. doi: 10.1016/j.conb.2014.06.009

Conflict of Interest Statement: The authors declare that the research was conducted in the absence of any commercial or financial relationships that could be construed as a potential conflict of interest.

Copyright (c) 2017 Negwer and Schubert. This is an open-access article distributed under the terms of the Creative Commons Attribution License (CC BY). The use, distribution or reproduction in other forums is permitted, provided the original author(s) or licensor are credited and that the original publication in this journal is cited, in accordance with accepted academic practice. No use, distribution or reproduction is permitted which does not comply with these terms. 